\title{
ANNALS
}

OF THE

\section{RHEUMATIC DISEASES}

\section{METABOLISM, TOXICITY AND MANNER OF ACTION OF GOLD COMPOUNDS USED IN THE TREATMENT OF ARTHRITIS}

\section{III.-COMPLETE EXCRETION STUDIES AND COMPARI- SON OF INTRAVENOUS AND INTRAMUSCULAR ADMINISTRATION OF SOME GOLD SALTS}

BY R. H. FREYBERG, WALTER D. BLOCK AND S. LEVEY From the Rackham Arthritis Research Unit,* the Medical School, University of Michigan, Ann Arbor

OUR investigations of the metabolism of gold were begun several years ago in an attempt to solve some of the mysteries concerned with the manner of action and toxicity of various gold salts employed in the treatment of arthritis. It seemed reasonable that, if more complete information were available regarding the fate of gold administered to humans in different ways, the relative value of different types of gold preparations could be more scientifically ascertained and improved methods of administration of such drugs would result.

To accomplish these studies, special methods of quantitative gold analysis were developed. However, successful analysis of the gold content of fæces was not possible until considerable information had been obtained regarding the plasma and synovial fluid concentrations of gold and the urinary excretion of gold. Consequently, these results were reported separately as they were observed following the treatment of patients with rheumatoid arthritis with gold sodium thiomalate (myochrysine), gold sodium thiosulphate, and colloidal gold sulphide. Much valuable information resulted from these earlier studies. However, they did not include fæcal gold analyses, and whenever administered parenterally the salts were injected intramuscularly. When the

* The Rackham Arthritis Research Unit is supported by the Horace H. Rackham School of Graduate Studies of the University of Michigan. 
technical advances permitted, we studied more patients in a similar fashion, but made complete excretion studies, including the fæcal gold elimination. Comparison was also made of the intramuscular and intravenous routes of administration of some gold salts. It is the purpose of this communication to report the results of these extended studies.

\section{MethodS}

Patients with rheumatoid arthritis were studied, using a plan of investigation and technical procedures precisely the same as employed in our earlier investigations. ${ }^{1}$ Fæcal gold was determined by. the method of Block and Buchanan., 3 Usually analyses of daily accumulated fæces were made; occasionally two or three days' eliminations were pooled, analysed and reported as average daily excretions.

\section{Rrsults}

In Fig. 1 are the results obtained in subject A. B., which are characteristic of those of all patients to whom gold sodium thiomalate* was given intramuscularly. The plasma concentration and urinary excretion of gold were similar to those previously reported in other subjects treated with this salt. The fæces contained much less gold than did the urine. The fæcal excretion increased slightly as the amount of gold injected increased. There was some variation from day to day, and it is conspicuous that during the twenty-four-hour period following injections of gold salt the fæcal excretion was not greater than on other days; this distinctly contrasts with the urinary elimination of gold. During the seven days following the injection of $40 \mathrm{mg}$. of gold (on the eighteenth day) the urinary excretion of gold was only $7.5 \mathrm{mg}$., and the fæcal excretion only $2 \mathrm{mg}$. Thus only 24 per cent. of the injected gold was eliminated before another injection was given, following which there was still greater retention. From our earlier studies, when only urinary excretion was measured, it was evident that there was considerable retention of gold during the period when the gold salt was being administered; now with these complete excretion data, the exact amount of retention of gold is definitely known, and is found to be approximately 75 per cent. of the amount administered. Jersey.

* Myochrysine, marketed by Merck and Company, Rahway, New 
Fig. 2 contains results obtained when gold sodium thiosulphate* was injected intramuscularly. In this particular patient blood concentrations were lower than commonly observed with this salt; the urine values are of the usual magnitude. ${ }^{1}$ It should be observed that with this gold preparation also the amount of gold excreted in the fæces was much less than that in

GOLD IN PLASMA, URINE, \& FECES

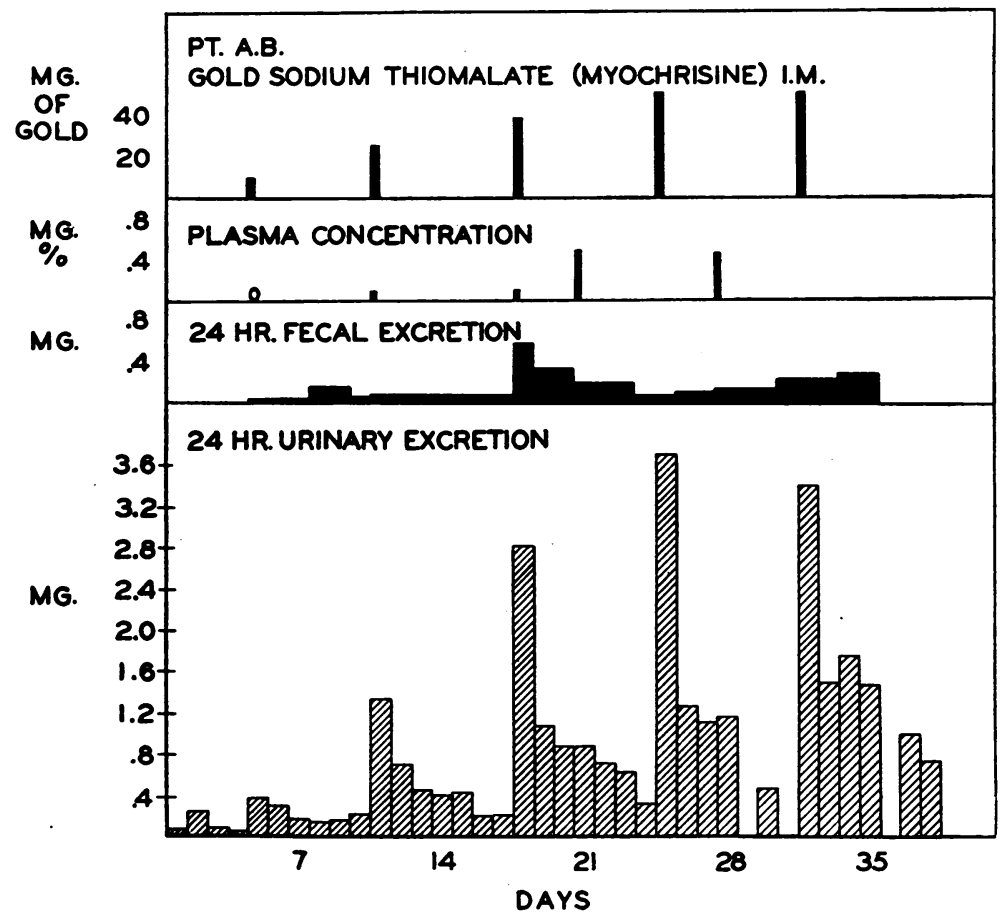

Fiaure 1.-Plasma concentration and the excretion of gold in the urine and fæces of a patient treated with gold sodium thiomalate (myochrysine) injected intramuscularly at weekly intervals. Increasing doses were employed until the dose contained $50 \mathrm{mgm}$. of gold.

the urine, and that the fæcal excretion increased as the amount injected increased, but it did not continue to rise after the weekly dose remained constant, even though the gold was being retained. The fæcal gold values are slightly higher in this patient than were found after injection of gold sodium thiomalate (Fig. 1). With the use of this salt also, during the period of administration, most of the gold injected is retained in the body. In general,

* Supplied for this study by G. D. Searle and Company, Chicago, Illinois. 
the metabolism of gold is similar following intramuscular injections of gold sodium thiomalate and gold sodium thiosulphate.

Several patients were given gold sodium thiosulphate intravenously in order to contrast results with the intramuscular route of administration. In Fig. 3 the results of intravenous and intramuscular injections in the same patient are shown. During the period of increasing intravenous doses the plasma

GOLD IN PLASMA URINE \& FECES

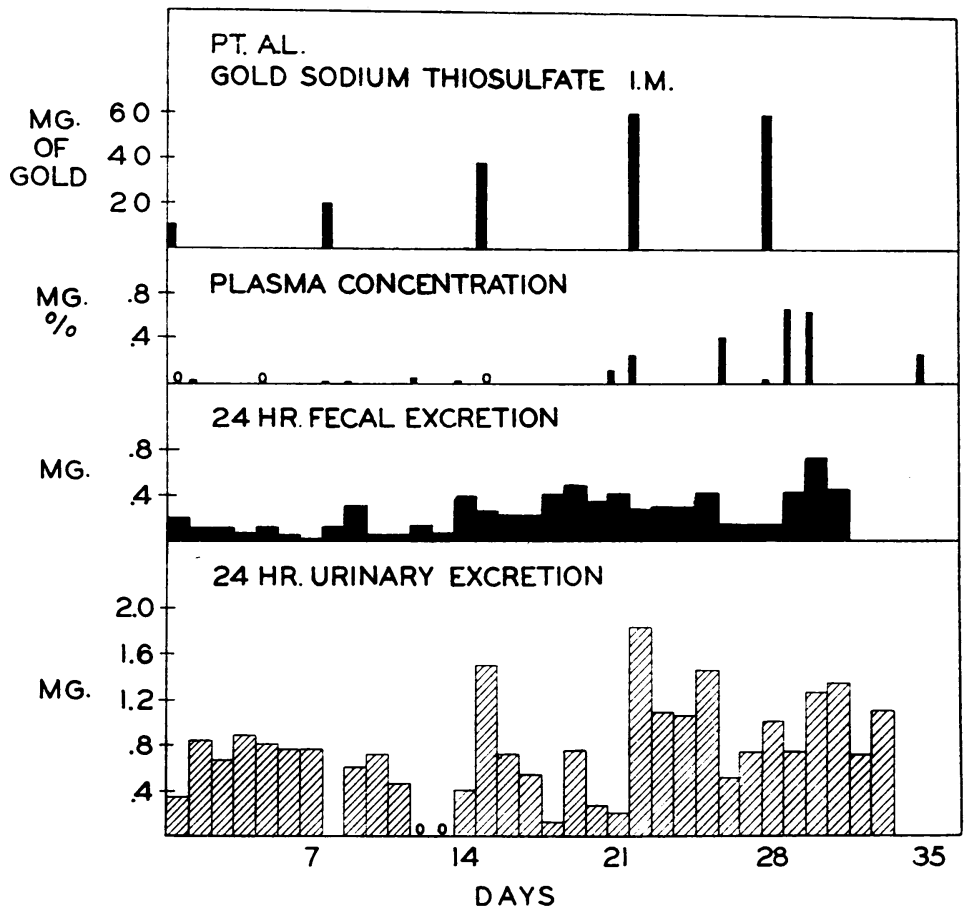

FIGURE 2.-Plasma concentration and the excretion of gold in the urine and fæces of a patient treated with gold sodium thiosulphate injected intramuscularly at weekly intervals. Increasing doses were employed until the dose contained $60 \mathrm{mgm}$. of gold.

concentration and the urinary excretion of gold were essentially the same as observed in other patients given the salt intramuscularly. Most significant is the fact that the plasma concentration and the urinary and fæcal excretion of gold were essentially the same when the same amount of the gold salt was injected, whether it was given intravenously or intramuscularly. In a week following the injection of $40 \mathrm{mg}$. of gold intravenously and also intramuscularly 24 per cent. was eliminated, 76 per cent. 
retained. These values are identical with the results following injection of the same amount of gold as gold sodium thiomalate.

Another interesting finding in connection with the studies following intravenously injected gold sodium thiosulphate was that the blood concentration and urinary excretion during the first few hours after injection (Fig. 4) were similar to those following the intramuscular injection of this salt, reported previously. ${ }^{1}$ This observation indicates the relatively quick

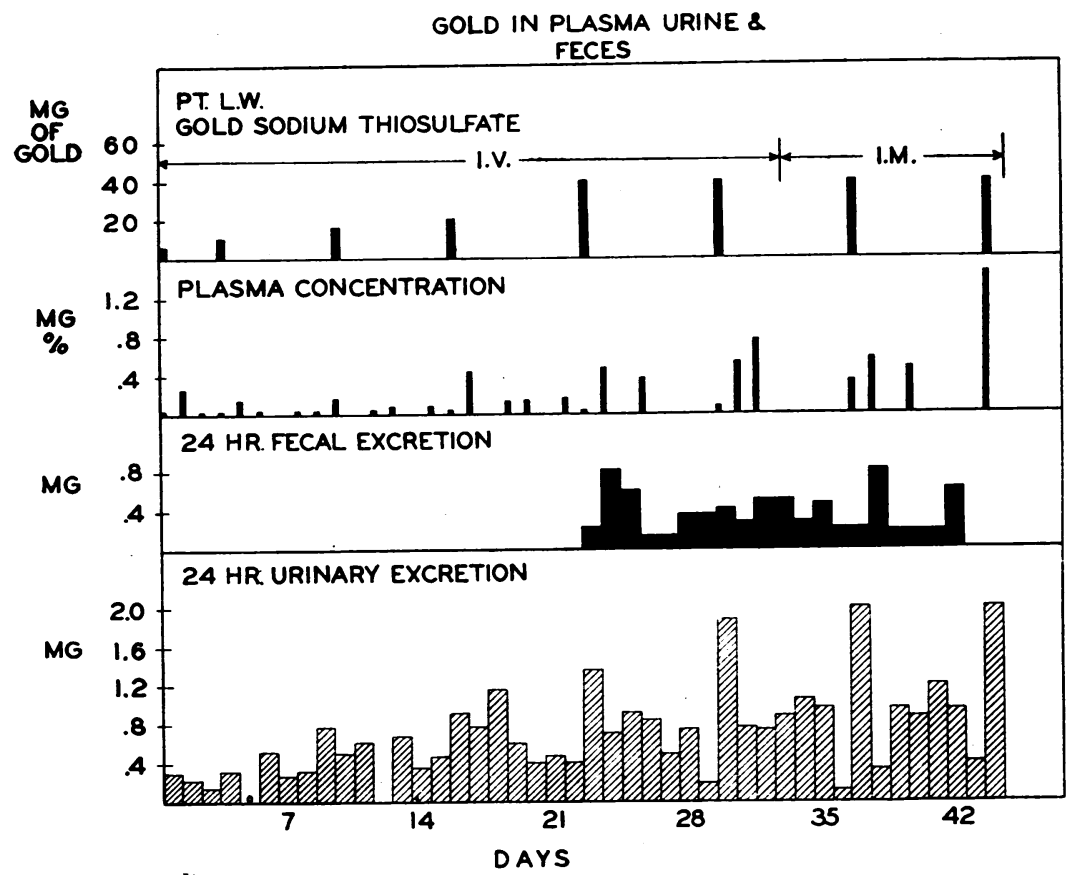

Figure 3.-Plasma concentration and the excretion of gold in the urine and fæces of a patient treated with gold sodium thiosulphate injected at weekly intervals at first intravenously, then intramuscularly. Increasing doses were employed until the dose contained $40 \mathrm{mgm}$. of gold, at which level it remained throughout the remainder of the study.

absorption of this soluble gold salt when it is given intramuscularly. One hour after the intravenous injection the plasma gold concentration was only slightly higher than observed two, three and four hours after injection, thus indicating the slow rate at which gold leaves the blood stream.

In earlier studies it was found that most patients given colloidal gold sulphide* orally or intramuscularly had very low

* Aurol Sulphide, supplied for this study by Hille Laboratories, Chicago, Ilinois. 
plasma gold concentrations, and eliminated little gold in the urine. The present investigations substantiate our earlier results, and further indicate that the fæcal excretion of gold following administration of this colloidal suspension is exceedingly small. Findings in a typical case appear in Fig. 5. After twelve intramuscular injections of colloidal gold sulphide, each containing $38 \mathrm{mg}$. of gold, the plasma contained only traces of gold, and after

TWENTY-FOUR HOUR PERIODS FOLLOWING ADMINISTRATION

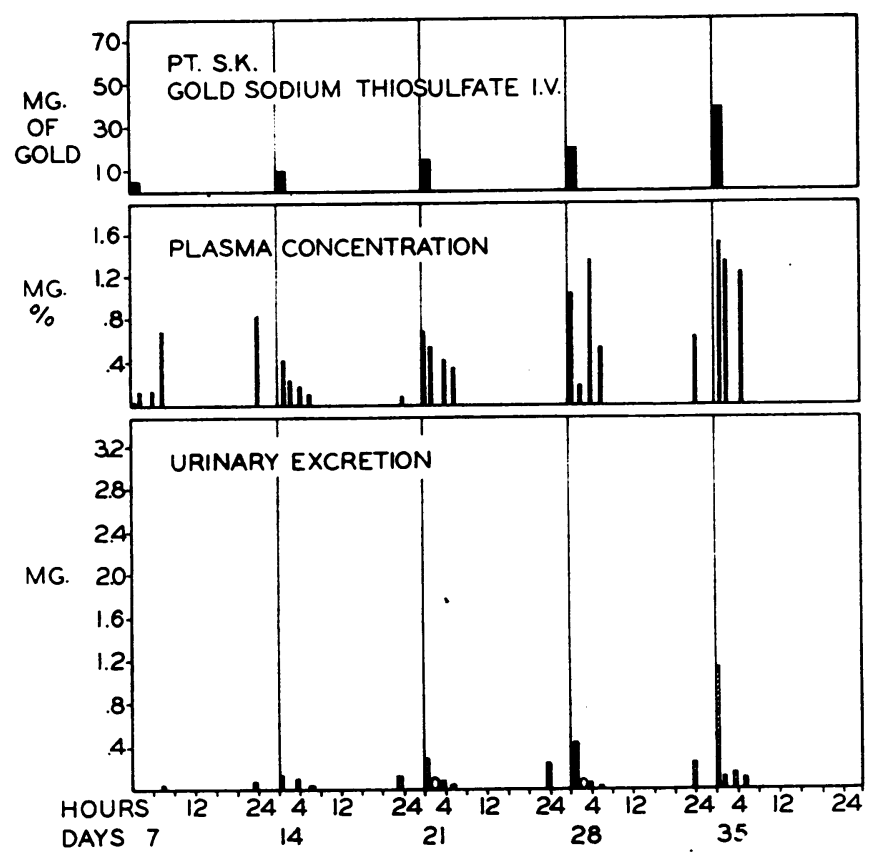

Figure 4.-Plasma gold content at one, two, four', six and twenty-four hours after the intravenous injection of gold sodium thiosulphate, and the gold content of the urine formed between the time of blood analyses. The injections are indicated by the vertical lines extending through the graph.

sixteen injections the fæcal gold values were very small. The urinary output of gold was measured for seven days; on four days no gold was found in the urine. Results in other patients were similar.

Most surprising results were obtained after intravenous injections of colloidal gold sulphide. The data in Fig. 6 show that after a single large injection of colloidal gold sulphide containing $50 \mathrm{mg}$. of gold the plasma contained little or no gold during the 
GOLD IN PLASMA, URINE \& FECES

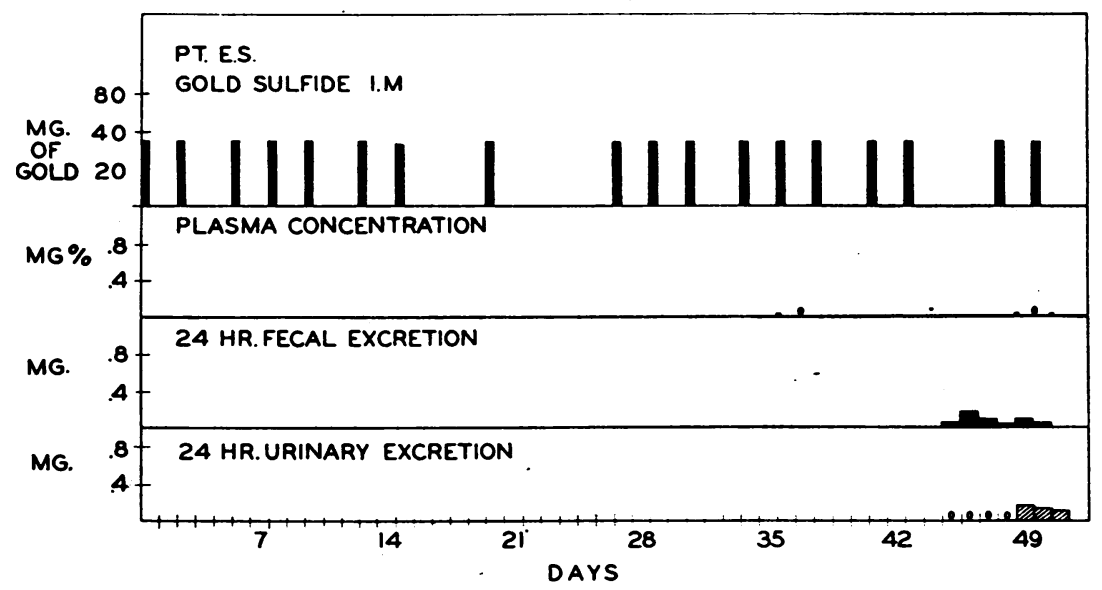

Fraure 5.-Plasma concentration and the excretion of gold in the urine and fæces of a patient treated with colloidal gold sulphide injected intramuscularly in doses containing $38 \mathrm{mgm}$. of gold.

GOLD IN PLASMA, URINE \& FECES

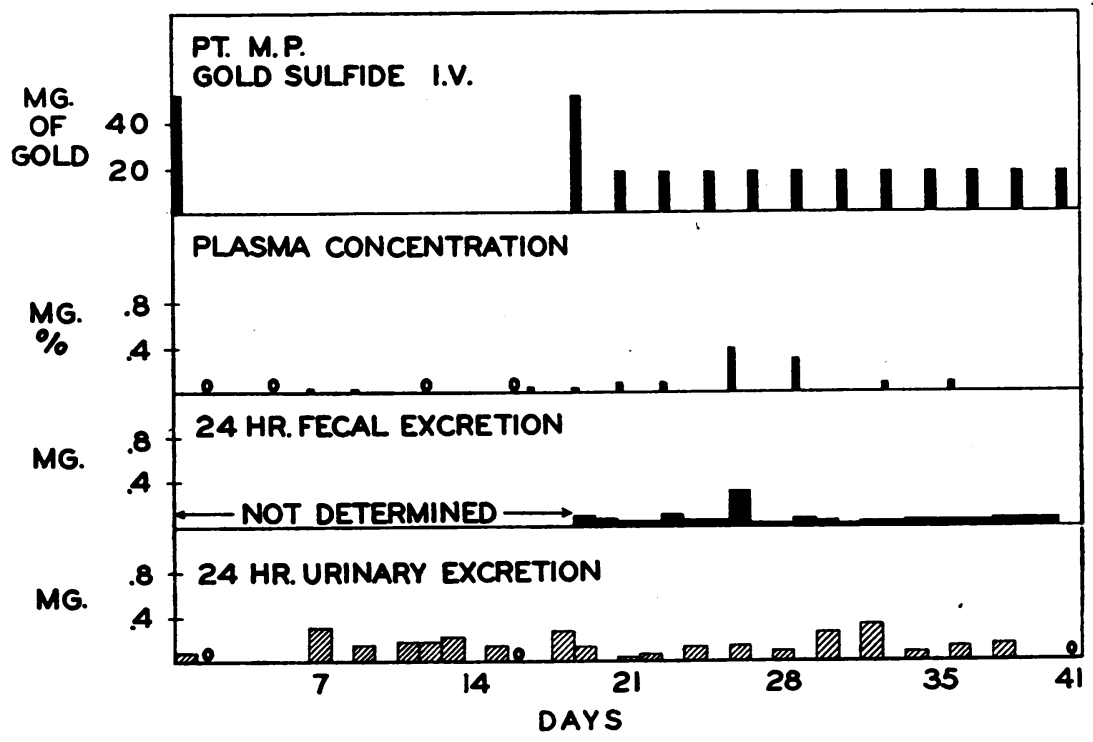

Figure 6.-Plasma concentration and the excretion of gold in the urine and fæces of a patient treated with colloidal gold sulphide injected intravenously. 
following eighteen days; the excretion of gold in the urine was much less than occurred after the same amount of gold was injected as gold sodium thiomalate or gold sodium thiosulphate. When colloidal gold sulphide was injected intravenously in amounts supplying $20 \mathrm{mg}$. of gold every second day, the plasma concentration was slightly greater than after the single larger injection, but the excretion of gold in urine and fæces was small.

Another patient, S. A. (Fig. 7), was given large amounts of colloidal gold sulphide intravenously, the last injection containing

GOLD IN PLASMA, URINE \& FECES

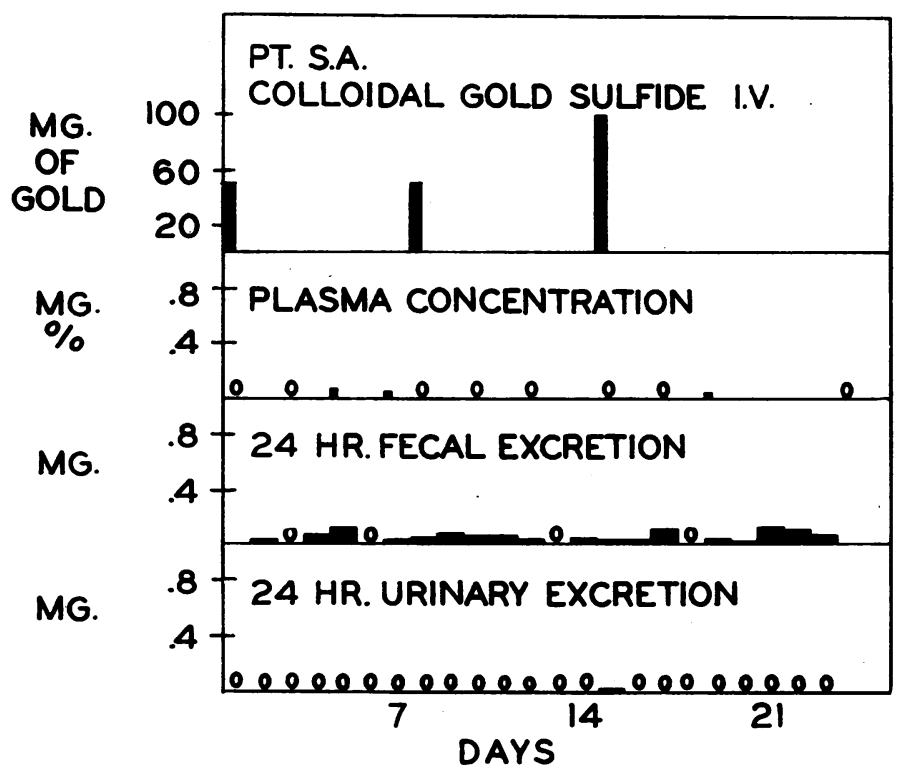

FIgURE 7.-Plasma concentration and the excretion of gold in the urine and fæces of another patient treated with colloidal gold sulphide injected at weekly intervals intravenously.

$100 \mathrm{mg}$. of gold. Frequent morning samples of plasma contained either no gold or only traces; the urine contained no gold except a trace on two days, and the fæces contained very small amounts of gold. Specimens of plasma and urine obtained at short intervals after intravenous injection of colloidal gold sulphide were analysed (Table I). In subject S. A. the injected gold had disappeared entirely or was present only in traces as early as thirty minutes after injection; the urine contained no gold and the fæces only traces. Similar results were observed in M. P. 
Table I.-The Plasma Gold Concentration and Excretion of Goud DURING THE TWENTY-FOUR HOURS AFTER THE INTRAVENOUS InJeCtion of Collomal Gold Sulphide.

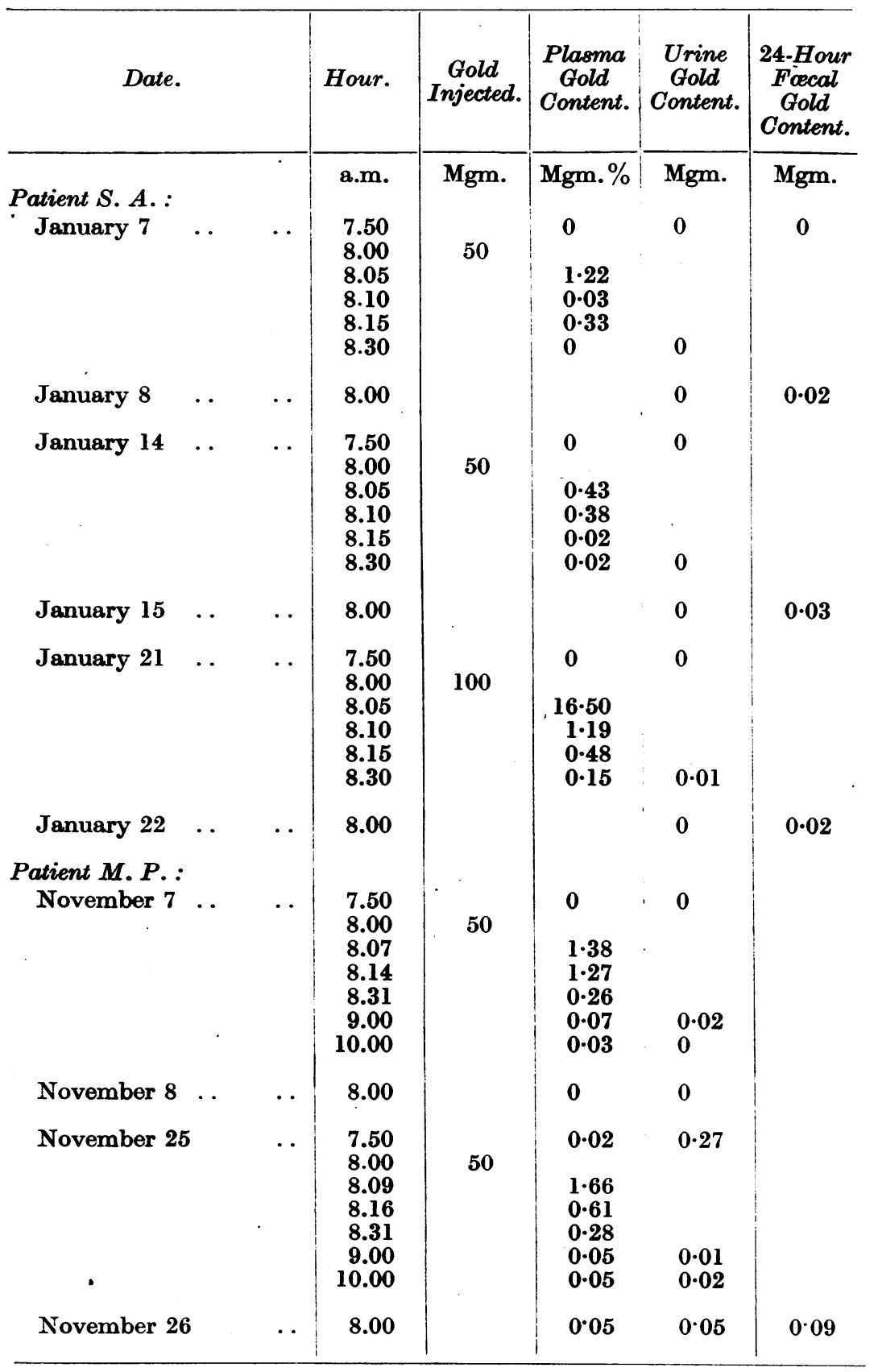


Continuous excretion studies conducted in seven patients using gold sodium thiomalate, gold sodium thiosulphate, and colloidal gold sulphide are summarised in Table II. Results were similar with the first two salts; the gold of these salts was excreted chiefly in the urine and the retention ranged from 77 to 88 per cent. But in the case of colloidal gold sulphide more than 99 per cent. of the gold was retained and the excretion was chiefly in the fæces.

\section{Discussion}

It was evident from our earlier studies, when urinary excretion only was measured, that considerable retention of gold occurred during the period of its administration. From the present investigations, which include the determination of gold in fæces as well as in the urine, the retention was accurately measured and found to be great. During the many weeks when gold sodium thiomalate and gold sodium thiosulphate were injected the total excretion of gold was never more than 23 per cent.; usually it was between 10 and 15 per cent. of the amount injected. The retention of gold given as colloidal gold sulphide was usually greater than with the crystalline salts, regardless of the route of administration.

The chemical aspects of blood, urine and fæces obtained after the intravenous injection of gold sodium thiosulphate are essentially the same as when this salt is given intramuscularly, indicating that the absorption from muscle depots is rapid and that the metabolism of gold given as this salt is not appreciably affected by the route of administration. The finding of only 3.64 per cent. of the gold injected as gold sodium thiosulphate in the muscles of rats one day after injection, ${ }^{4}$ is further evidence of the rapid absorption.

Even when injected directly into the blood stream, a large part of the gold is retained in body tissues for a long time. Details of this retention are being studied.4, 5

Since our metabolism data show close sîmilarity between gold sodium thiomalate and gold sodium thiosulphate, it seems correct to conclude that the absorption of gold given intramuscularly as the thiomalate salt is rapid and quite complete. This conclusion is supported by the finding of only 7.6 per cent. of the gold injected into the muscles of white rats in the form of gold sodium thiomalate to be present at the site of injection one day later. 
TREATMENT OF ARTHRITIS

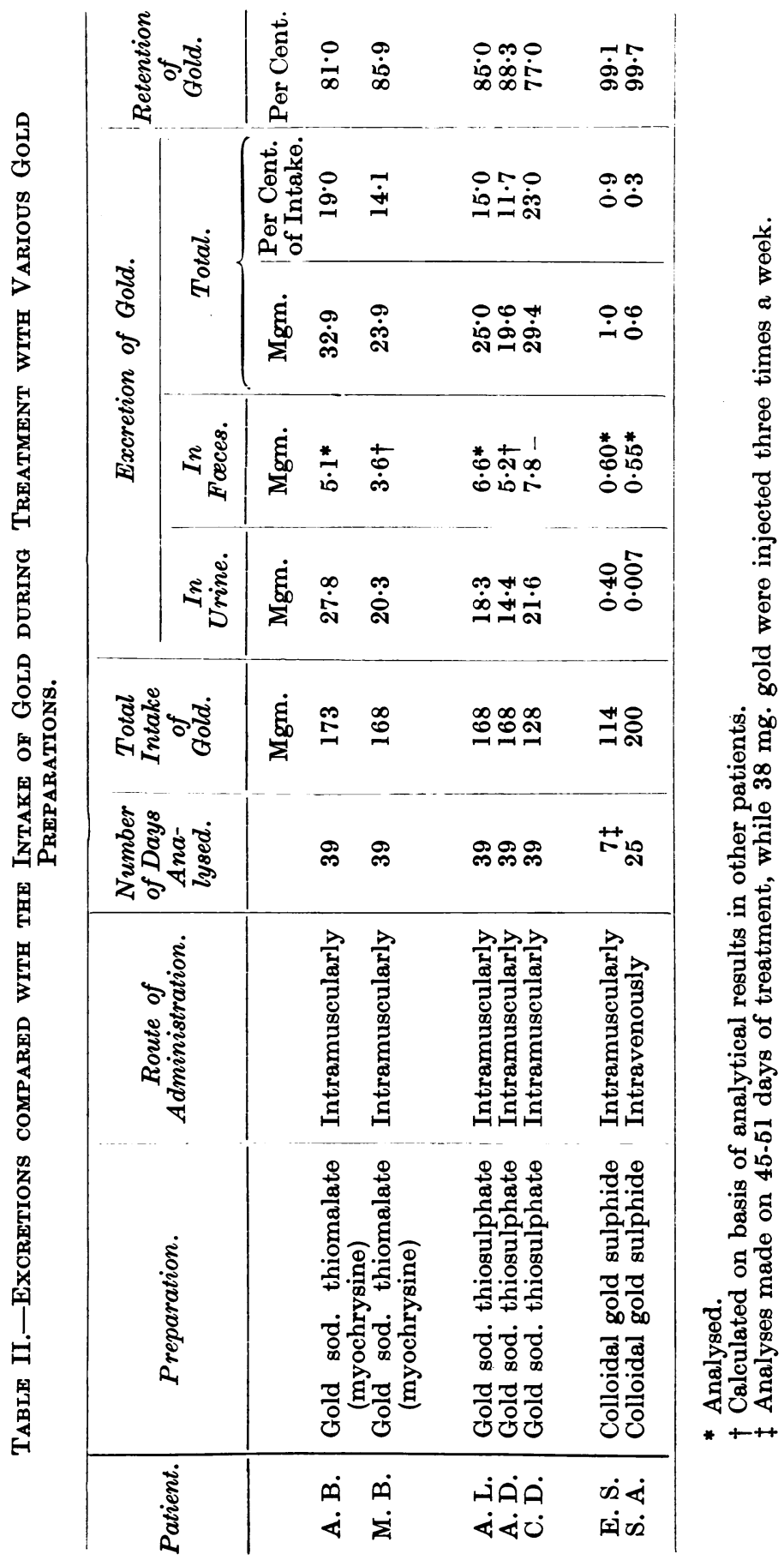


From our earlier investigation we suspected the low plasma and urinary excretion values observed when colloidal gold sulphide was given orally or intramuscularly were due to poor absorption. However, the data of this report show rapid disappearance of gold from the blood after the intravenous injection of this colloidal preparation, and it is not excreted. Animal investigations have shown that reticulo-endothelial cells of the liver and spleen contain huge amounts of precipitated gold after this colloid gold sulphide was injected. ${ }^{6}$ It seems clear, therefore, that the rapid disappearance of intravenously injected colloidal gold sulphide is due to phagocytosis by reticulo-endothelium. In this respect this colloidal gold salt behaves like other colloidal suspensions injected intravenously. Because of this, it seems obvious that colloidal preparations of gold or gold salts are not advantageous, nor are they to be recommended for treatment.

\section{SUmmary aNd Conclusions}

Further investigations of the metabolism of gold used in the treatment of rheumatoid arthritis, including complete excretion studies and a comparison of effects following the intravenous and intramuscular injections of some gold salts, are reported.

During the period of administration of gold sodium thiomalate and gold sodium thiosulphate the fæcal excretion of gold is much less than the urinary elimination, ranging from 12 to 25 per cent. of the total excretion. Following the injection of colloidal gold sulphide, the total excretion is much less than that found after the injection of the crystalline salts, but the percentage in fæces is considerably greater. These complete excretion studies show that gold is retained in large amounts during the period of treatment; the retention ranged from 77 to 88 per cent. with the crystalline salts, and often more than 99 per cent. with colloidal gold sulphide.

When gold sodium thiosulphate is used, the plasma content and excretion of gold are essentially the same whether the drug is given intravenously or intramuscularly. Therefore the factor of absorption from a muscle depot has no important influence on the metabolism of this crystalline gold salt, and probably also not on the metabolism of gold sodium thiomalate.

Within thirty minutes after an intravenous injection of a large amount of colloidal gold sulphide the plasma may contain little or no gold, and the amount excreted during this period is 
very. small or none. After many intravenous injections of this preparation the plasma gold concentration and excretion of gold are small and similar to the values usually observed following oral or intramuscular administration. These results are due to quick phagocytosis of the colloidal gold salt by reticulo-endothelial cells.

\section{REFERENCES}

1. Freyberg, R. H., Block, W. D., and Levey, S.: " Metabolism, Toxicity and Manner of Action of Gold Compounds used in the Treatment of Arthritis. I. Human Plasma and Synovial Fluid Concentration and Urinary Excretion of Gold during and following Treatment with Gold Sodium Thiomalate, Gold Sodium Thiosulphate and Colloidal Gold Sulphide." J. Clin. Investigation, 1941, 20, 401. (See Annals Rheum. Dis., Vol. II., No. 4, p. 279.)

2. Block, W. D., and Buchanan, O. H.: "The Micro-determination of Gold in Biological Fluids." $J$. Biol. Chem., 1940, 136, 379.

3. Block, W. D., and Buchanan, O. H.: "The Micro-determination of Gold in Tissues and Excreta." To be published.

4. Block, W. D., Buchanan, O. H., and Freybere, R. H.: "Metabolism, Toxicity and Manner of Action of Gold Compounds in the Treatment of Arthritis. II. A Comparative Study of the Distribution and Excretion of Gold following the Intramuscular Injection of Five Different Gold Compounds." J. Pharm. Exptl. Therap., 1941, 73, 200.

5. Unpublished data.

6. Freyberg, R. H., Block, W. D., and Buchanan, O. H.: " Metabolism, Toxicity and Manner of Action of Gold Compounds used in the Treatment of Arthritis. IV. Histologic Changes in Rats effected by Gold Sodium Thiomalate, Gold Sodium Thiosulphate, Colloidal Gold, Colloidal Gold Sulphide and Sodium Succinimido Aurate." To be published.

\section{RESISTANCE IN RHEUMATISM}

\section{BY WILLIAM HUGHES}

CURRENT conception of the mechanism of a disease such as rheumatism postulates the existence of an infective agent which "acts on" or "attacks" the tissues and "produces" a lesion. Certain factors such as age, sex, the presence of septic foci, glandular dysfunction, etc., contribute by lowering the "resistance." In this vague concept all the terms in inverted commas are capable of more than one interpretation, but the one which has caused most confusion in the study of rheumatism is "resistance." This term has been stretched to accommodate the most contradictory hypotheses in the rtiology of the disease, and some promising methods of treatment have been emasculated 